\title{
Synthesis of plastic Zr-based bulk metallic glass matrix composites by the copper-mould suction casting and the Bridgman solidification
}

\author{
J.W. Qiao ${ }^{\mathrm{a}}$, Y. Zhang ${ }^{\mathrm{a}, *}$, Z.L. Zheng ${ }^{\mathrm{a}}$, J.P. He ${ }^{\mathrm{a}}$, B.C. Wei ${ }^{\mathrm{b}}$ \\ a State Key Laboratory for Advanced Metals and Materials, University of Science and Technology Beijing, Beijing 100083, China \\ ${ }^{\mathrm{b}}$ National Microgravity Laboratory, Institute of Mechanics, Chinese Academy of Sciences, Beijing 100080, China
}

\section{A R T I C L E I N F O}

\section{Article history:}

Received 9 July 2008

Received in revised form

29 September 2008

Accepted 2 October 2008

Available online 21 November 2008

\section{Keywords:}

Bridgman solidification

Composites

Plasticity

Shear bands

\begin{abstract}
A B S T R A C T
Zr-based bulk metallic glass matrix composites with the composition of $\mathrm{Zr}_{56.2} \mathrm{Ti}_{13.8} \mathrm{Nb}_{5.0} \mathrm{Cu}_{6.9} \mathrm{Ni}_{5.6} \mathrm{Be}_{12.5}$ were synthesized by the copper-mould suction casting and the Bridgman solidification. The composite, containing a well-developed flowery $\beta$-Zr dendritic phase, was obtained by the Bridgman solidification with the withdrawal velocity of $0.8 \mathrm{~mm} / \mathrm{s}$ and the temperature gradient of $45 \mathrm{~K} / \mathrm{mm}$, and the ultimate strength of $2050 \mathrm{MPa}$ and fracture plastic strain of $14.6 \%$ of the composite were achieved, which was mainly interpreted by the homogeneous dispersion of bcc $\beta$-Zr phase in the glass matrix.
\end{abstract}

Crown Copyright (c) 2008 Published by Elsevier B.V. All rights reserved.

\section{Introduction}

Recently, many new kinds of metallic alloys have been developed [1-5]. Among these alloys, bulk metallic glasses (BMGs) possess many excellent properties including high strength, high elastic strain limits, and high corrosion resistance [6-8], which renders them potential candidates for use as engineering materials. Under unconstrained conditions, however, almost all BMGs confront a fateful problem in that they usually fail by the formation of highly localized shear bands, leading to catastrophic failure without obvious macroscopic plasticity.

To overcome the catastrophic failure and improve the ductility of BMGs, the formation of the multiple shear bands on the whole samples upon loading is necessary. Generally, the bulk metallic glass matrix composite, combining the glass matrix with metallic or ceramic reinforcements of various morphologies, can achieve it. The first of these composites were to add the solid phases to the molten matrix through ex situ process [9,10]. Later, a series of in situ composites were developed, which consist of an amorphous matrix embedding ductile dendrites that formed during cooling of the melt by nucleation and dendritic growth of a bcc solid solution, followed by the solidification of the remaining liquid alloy

\footnotetext{
* Corresponding author. Tel.: +86 1062334927 ; fax: +86 1062333447.

E-mail address: drzhangy@skl.ustb.edu.cn (Y. Zhang).
}

[11-14]. These in situ composites exhibit large compressive plasticity and some tensile ductility together with the improved impact toughness compared to monolithic BMGs $[11,14]$. Upon loading, multiple shear bands are generated in the glass matrix of the composites so that the catastrophic instability along the localized shear bands can be avoided. Usually, the size, morphology and distribution of the ductile phase are crucial for the inhibition of critical shear bands. The formation of the ductile phase is influenced by the cooling conditions of the melt, i.e. the thermal conduction and extraction. For mm-sized samples synthesized by the copper-mould suction casting, the resultant microstructures are inhomogeneous along the radius of the rods, since different cooling rates are produced from the outer surface to the center. Therefore, a ring-shaped sample is obtained, which may lead to a deviation of characterization of mechanical properties. In this letter, a Zr-based bulk metallic glass composite will be synthesized by the Bridgman solidification in order to achieve a uniform microstructure [15-18]. By varying the withdrawal velocities in a controlled manner, the composite with a tailorable fraction and homogeneous distribution of flowery dendritic phase can be obtained. Here the Zr-based metallic glass matrix composite with the composition of $\mathrm{Zr}_{56.2} \mathrm{Ti}_{13.8} \mathrm{Nb}_{5.0} \mathrm{Cu}_{6.9} \mathrm{Ni}_{5.6} \mathrm{Be}_{12.5}$ was fabricated by the Bridgman solidification with the withdrawal velocity of $0.8 \mathrm{~mm} / \mathrm{s}$ at a temperature gradient of about $45 \mathrm{~K} / \mathrm{mm}$. The microstructures and mechanical properties of the composites fabricated by the copper-mould suction casting and the Bridgman solidification will be compared in this study. 


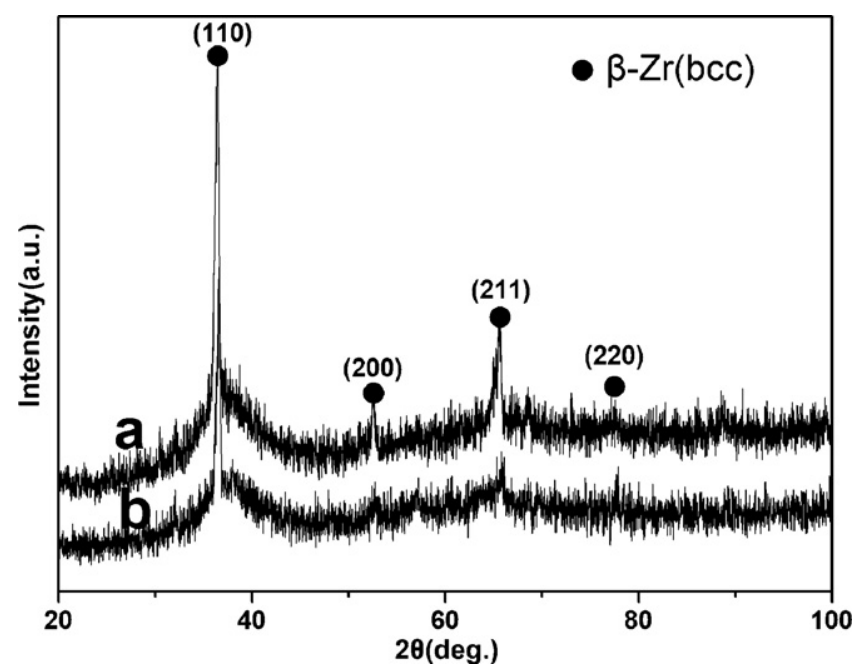

Fig. 1. XRD patterns of the alloys synthesized by (a) the copper-mould suction casting and (b) the Bridgman solidification.

\section{Experimental procedure}

The ingot with nominal atomic percent composition of $\mathrm{Zr}_{56.2} \mathrm{Ti}_{13.8} \mathrm{Nb}_{5.0} \mathrm{Cu}_{6.9}$ $\mathrm{Ni}_{5.6} \mathrm{Be}_{12.5}$ was prepared by arc melting the mixture of $\mathrm{Zr}$, $\mathrm{Ti}, \mathrm{Nb}, \mathrm{Cu}, \mathrm{Ni}$ and Be with purity higher than 99.99 weight percent in a Ti-getted high purity argon atmosphere. In order to ensure the compositional homogeneity, a four-step melting procedure was adopted: firstly, elemental $\mathrm{Nb}$ and $\mathrm{Zr}$ were melted together, followed by the addition of Be. Secondly, elemental $\mathrm{Cu}, \mathrm{Ni}$ and $\mathrm{Ti}$ were melted together in a second batch, and finally both ingots were melted together and remelted several times until a homogeneous sample was formed. The liquid alloys were suctioned into a copper mould with a cylinder diameter of $3 \mathrm{~mm}$ and length of about $70 \mathrm{~mm}$ and another ingot was crashed into pieces and placed in an alumina tube with an internal diameter of $3 \mathrm{~mm}$ and a wall thickness of $0.5 \mathrm{~mm}$, and the Bridgman solidification was carried out with the withdrawal velocity of $0.8 \mathrm{~mm} / \mathrm{s}$ through a temperature gradient of about $45 \mathrm{~K} / \mathrm{mm}$ into the water-cooled Ga-In-Sn liquid alloys. For avoidance of the chemical reaction between the liquid alloy and the crucible at the high temperature, a proper coating in the inner wall of the crucible is adopted. The phase of the solidified rod was analyzed by X-ray diffraction (XRD) in a PHILIPS APD-10 diffractometer ( $\mathrm{Cu} K \alpha$ radiation). Thermal analysis was performed with a PerkinElmer DSC 7 differential scanning calorimeter under the argon atmosphere. A constant heating rate of $0.33 \mathrm{~K} / \mathrm{s}$ was employed and the sample was heated to $830 \mathrm{~K}$. The uniaxial compressive tests were performed on $6 \mathrm{~mm}$ long sections cut from the $3 \mathrm{~mm}$ diameter cylinders with MTS 809 materials testing machine at room temperature with a strain rate of $2 \times 10^{-4} \mathrm{~s}^{-1}$. On compression testing, compression samples were sandwiched between two WC platens, and two blades were mechanically fixed on the side surface of the WC platens. The longitudinal sections of the rod samples and the fracture surfaces and the side surfaces of the samples after compressive tests were investigated by scanning electron microscopy (SEM).

\section{Results and discussion}

The XRD patterns of the samples synthesized by the coppermould suction casting and the Bridgman solidification are presented in Fig. 1a and b, respectively. The curves show the sharp peak indicating a bcc $\beta$-Zr solid solution superimposed on a broad scattering feature characteristic of an amorphous phase. The crystal-plane indices of the $\beta$-Zr phase corresponding to peaks are marked and no other phases can be detected from the diffraction pattern of the composites. This result reveals that the composites are comprised of the bcc $\beta$-Zr solid solution and the glass matrix. Additionally, it is confirmed that the Bridgman solidification is also an effective way to synthesize bulk metallic glass matrix composites.

Fig. 2a exhibits the backscattered SEM image of the longitudinal section of the composite synthesized by the Bridgman solidification with the withdrawal velocity of $0.8 \mathrm{~mm} / \mathrm{s}$. In Fig. 2a, the morphology displays the well-developed flowery dendrites, uniformly dispersed in the glass matrix. An individual flowery dendrite, which has been cross-sectioned near its nucleation site, is illustrated in the inset of Fig. 2a and an estimate of the spanning length of $\sim 30 \mu \mathrm{m}$ is indicated by arrows. Fig. $2 \mathrm{~b}$ presents the backscattered SEM image of the cross-section of the composite developed by the coppermould suction casting and the spanning length of an individual dendrite is of $\sim 20 \mu \mathrm{m}$. It can be seen that the flowery dendrite is homogeneously distributed in the glass matrix for the sample obtained by the Bridgman solidification compared with the copper mold casting. Besides, the dendrites with high volume fraction, embedded in the glass matrix for the composites synthesized by the two methods, connect with each other forming a network, making it appear as though the glass has a heterogeneous instead of amorphous microstructure by close inspection. Although the estimate of the absolute volume fraction of the crystalline phase through the Image-tool analysis may lead to an unrealistic outcome, the relative volume fraction can be compared by analysis to the DSC results.

Fig. $3 a$ and $b$ displays the DSC traces of the composites synthesized by the Bridgman solidification with the withdrawal velocity of $0.8 \mathrm{~mm} / \mathrm{s}$ and the copper-mould suction casting, respectively. The two curves indicate the glass transition, followed by multiple exothermic events during continuous heating. The samples obtained by the Bridgman solidification and the copper-mould suction casting exhibit that the glass transition temperature, $\mathrm{Tg}$, are of $626 \mathrm{~K}$ and $612 \mathrm{~K}$, respectively and the onset temperature of first crystallization, $T_{\mathrm{x} 1}$, are of $655 \mathrm{~K}$ and $668 \mathrm{~K}$, respectively. Phase separation during the solidification from the high temperature molten depends on various factors, including the heat dissipation, which is closely related with the nucleation and growth of crystals. Therefore, different heat dissipation induces that solute elements,
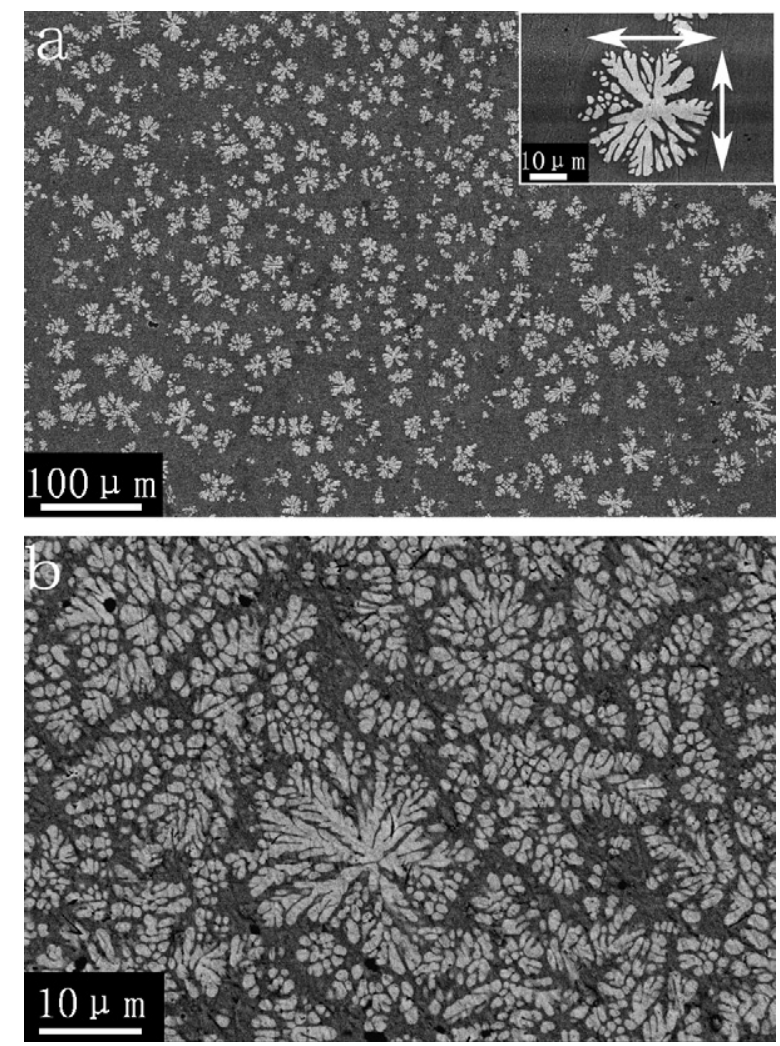

Fig. 2. Backscattered SEM images of (a) the longitudinal section of the composite synthesized by the Bridgman solidification with the withdrawal velocity of $0.8 \mathrm{~mm} / \mathrm{s}$ and (b) the cross-section of the composite synthesized by the copper-mould suction casting. The magnified morphology of individual dendritic phase is shown in the inset of (a). 


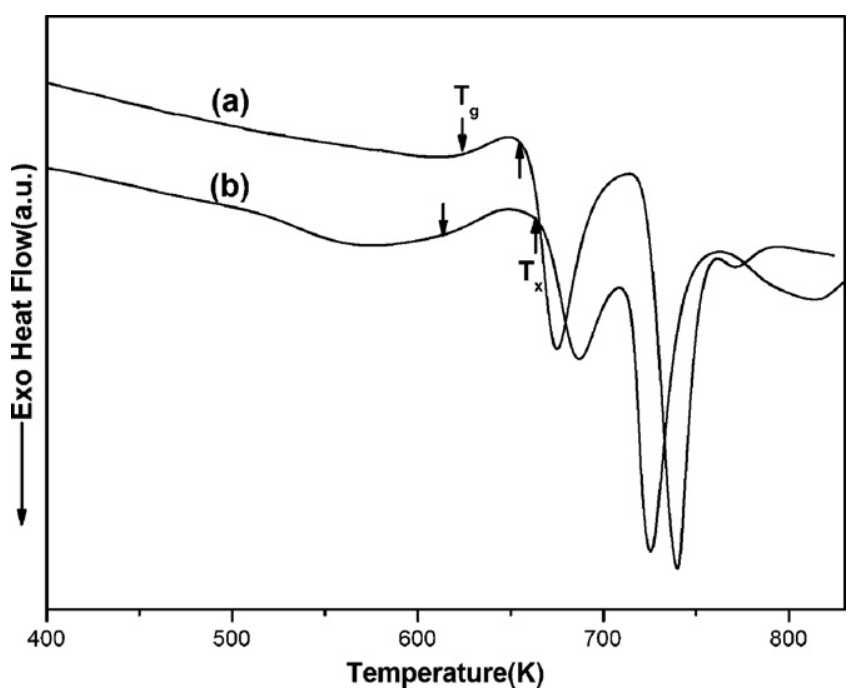

Fig. 3. DSC traces of the composites synthesized by (a) the Bridgman solidification with the withdrawal velocity of $0.8 \mathrm{~mm} / \mathrm{s}$ and (b) the copper-mould suction casting.

particularly the elemental $\mathrm{Nb}$, as a stabilizer for the formation of $\beta$-Zr solid solution, distribute differently in the $\beta$-Zr phase and the glassy matrix, which accounts for the different glass transition temperatures and the onset temperatures of first crystallization for the alloys obtained by the two methods. The integrated heat releases of crystallization during continuous heating to the samples obtained by the Bridgman solidification and the copper-mould suction casting are of $\sim 41 \mathrm{~J} \mathrm{~g}^{-1}$ and $\sim 32 \mathrm{~J} \mathrm{~g}^{-1}$, respectively, indirectly indicating the higher volume fraction of the $\beta$ - $\mathrm{Zr}$ phase corresponding to the copper-mould suction casting.

The compressive engineering stress-strain curves, obtained from uniaxial compressive tests for the $\mathrm{Zr}_{56.2} \mathrm{Ti}_{13.8} \mathrm{Nb}_{5.0} \mathrm{Cu}_{6.9} \mathrm{Ni}_{5.6}$

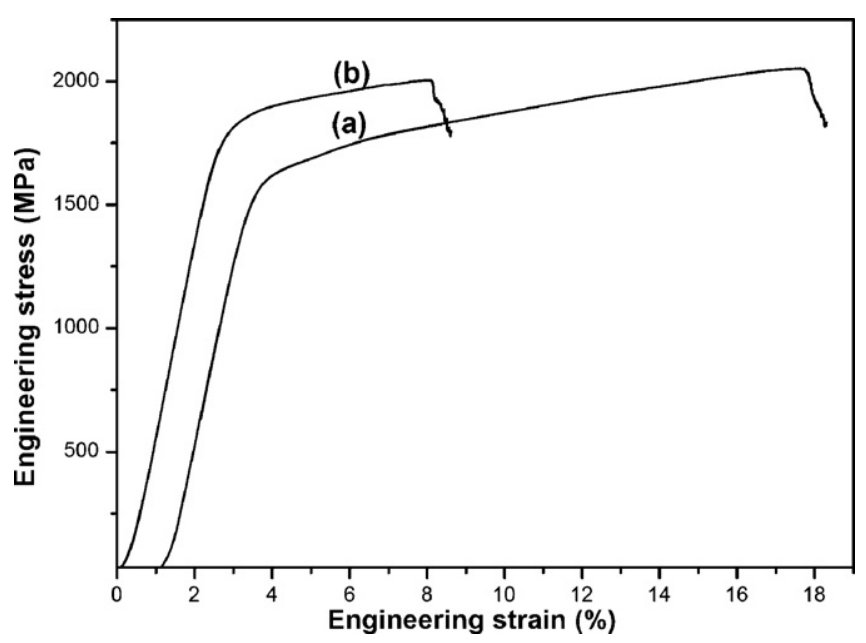

Fig. 4. Engineering stress-strain curves for the composites synthesized by (a) the Bridgman solidification with the withdrawal velocity of $0.8 \mathrm{~mm} / \mathrm{s}$ and (b) the coppermould suction casting.

$\mathrm{Be}_{12.5}$ bulk metallic glass composites synthesized by the Bridgman solidification and the copper-mould suction casting, are presented in Fig. 4a and b, respectively. It is shown that the yielding strength, the yielding strain, the ultimate strength, and the fracture plastic strain of the composite synthesized by the Bridgman solidification are of about $1270 \mathrm{MPa}, 2.0 \%, 2050 \mathrm{MPa}$, and $14.6 \%$, respectively, while they are of about $1420 \mathrm{MPa}, 2.1 \%, 2010 \mathrm{MPa}$, and $6.5 \%$, respectively, corresponding to the copper-mould suction casting. Compared with the mechanical properties of the composites fabricated by the copper-mould suction casting, the fracture plastic strain of the composite is greatly improved by the Bridgman solidification. It may be reasonable to deduce that the improved room temperature plasticity is mainly attributed to the homogeneously
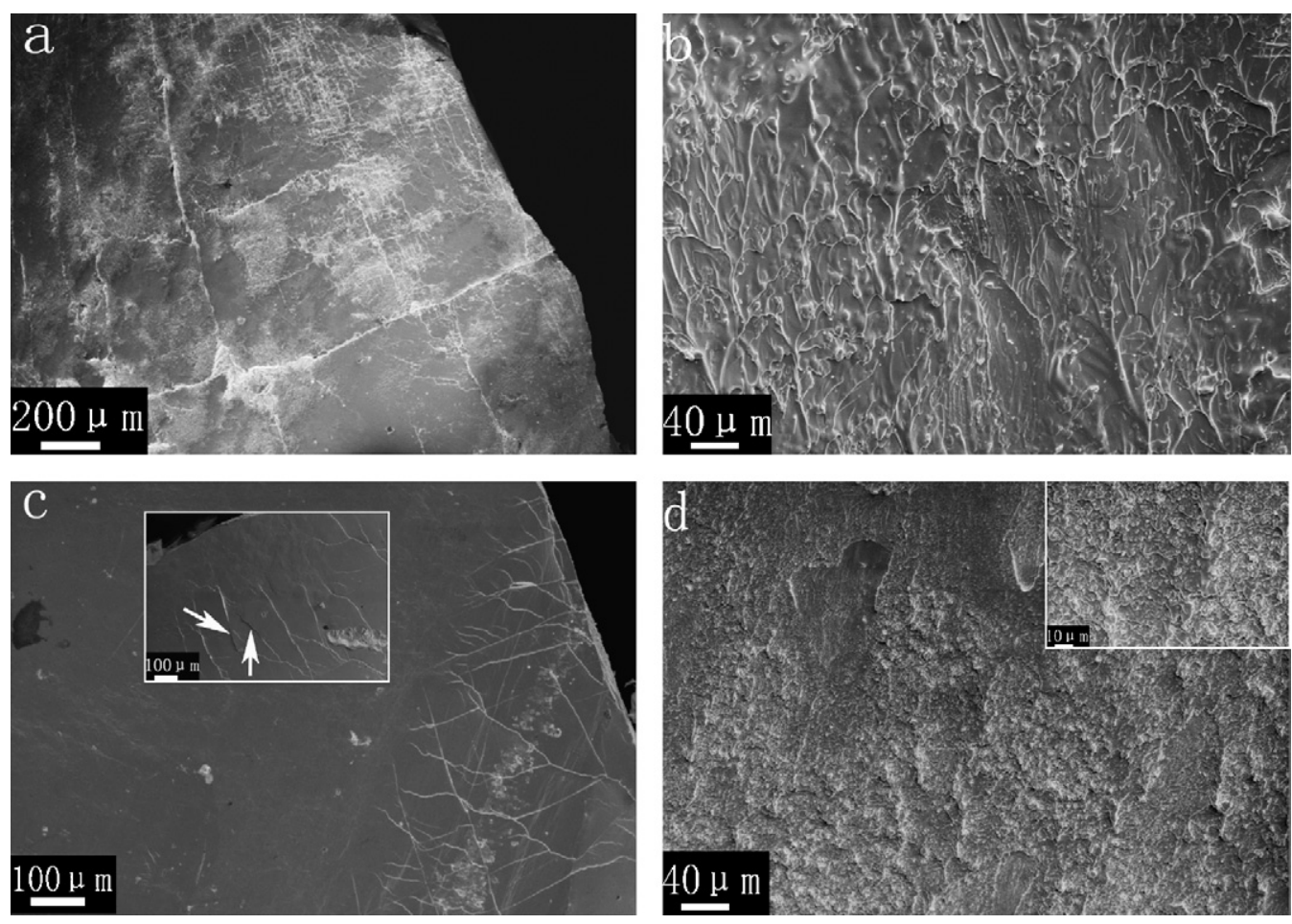

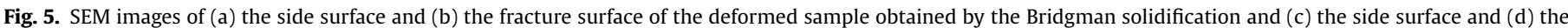
fracture surface of the deformed sample obtained by the copper-mould suction casting. 
dispersed bcc $\beta$-Zr phase and the size of distinctly flowery dendrites. Generally, the mechanical properties especially the plasticity of the bulk metallic glass matrix composites is closely related with the volume fraction of the crystalline phase [19-21]. Besides, the morphology and distribution of the crystalline phase also plays an important role in determining the mechanical properties [21-22]. Although the samples subjected to the copper-mould suction casting have a higher volume fraction of the ductile $\beta-\mathrm{Zr}$ phase, the inhomogeneous distribution of the secondary phase in the samples may give birth to a more pronounced effect on the plasticity. Upon loading, the $\beta-\mathrm{Zr}$ phase initially yields followed by the deformation of the glass matrix. Once the occurrence of the deformation of the glass matrix, there exists the generation and propagation of shear bands along the favorable direction. For the inhomogeneous microstructure of the samples, bigger gaps could appear among the $\beta-\mathrm{Zr}$ dendrites, which favorably aid to the propagation of shear bands in the glass matrix. However, the homogeneously distributed $\beta$-Zr phase forming the network structure, more effectively impedes the prompt propagation of shear bands, leading to the multiplication of shear bands. As a result, the plasticity of the composites is improved. Furthermore, the size of the individual $\beta-\mathrm{Zr}$ dendrites is larger for the sample developed by the Bridgman solidification than that by the copper-mould suction casting as mentioned above. The larger size of the crystalline phase also aids to the block of the rapidly proceeding shear bands.

To assist in analysis of the mechanical properties of the composites, the SEM images of the compressive fracture surface and the side surface are investigated in detail. The SEM image of the lateral surface of the deformed sample, developed by the Bridgman solidification, is shown in Fig. 5a. The coarser shear bands distributed near the crack are along perpendicular and parallel directions with respect to the fracture plane. In addition, the high number density of the finer shear bands distribute among the coarser shear bands, which is consistent with the large plasticity under compressive loading. Fig. $5 \mathrm{~b}$ displays the typical river-like pattern on the fracture surface of the sample subjected to the Bridgman solidification, characteristic of many BMG alloys and a lot of liquid drops could be observed on the fracture surface due to the adiabatic phenomena $[23,24]$. Few fine shear bands for the as-cast alloy, fabricated by the copper-mould suction casting, are localized near the crack as shown in Fig. 5c, and microcracks along the shear bands are exemplified in the inset of Fig. 5c (marked by the arrows), which indicates that the deformed sample underwent severe shear deformation. As shown in Fig. 5d, the fracture surface for as-cast alloy lays out the dropletlike feature and the high magnification of the dropletlike feature is illustrated in the inset of Fig. $5 d$, which indicates that the fracture surface is completely covered by the droplets related with fracture softening mechanism [25].

\section{Conclusions}

The microstructure and mechanical properties of the composites with the composition of $\mathrm{Zr}_{56.2} \mathrm{Ti}_{13.8} \mathrm{Nb}_{5.0} \mathrm{Cu}_{6.9} \mathrm{Ni}_{5.6} \mathrm{Be}_{12.5}$, containing plastic flowery dendritic phase, synthesized by the Bridgman solidification with the withdrawal velocity of $0.8 \mathrm{~mm} / \mathrm{s}$, are investigated in detail. Compared to the copper-mould suction casting, the well-developed flowery dendrites, homogeneously distributed in glass matrix, are obtained by the Bridgman solidification. The composite developed by the Bridgman solidification exhibits a large plasticity up to $\sim 14.6 \%$ before failure and the ultimate fracture strength of $\sim 2050 \mathrm{MPa}$, while the corresponding fracture plastic strain and the ultimate fracture strength are $\sim 6.5 \%$ and $2010 \mathrm{MPa}$ for the composite obtained by the copper-mould suction casting.

\section{Acknowledgements}

This work is supported by Program for New Century Excellent Talents in University (NCET-05-0105), National Natural Science Foundation of China (NNSFC) under the Grant No. 50571018 and ‘973 program' (Contract No. 2007CB613903).

\section{References}

[1] A. Peker, W.L. Johnson, Appl. Phys. Lett. 63 (1993) 2342.

[2] G. He, J. Eckert, W. Löser, L. Schultz, Nat. Mater. 2 (2003) 33.

[3] Y.L. Hao, S.J. Li, B.B. Sun, M.L. Sui, R. Yang, Phys. Rev. Lett. 98 (2007) 216405.

[4] W.B. Dong, H.F. Zhang, J. Cai, W.S. Sun, A.M. Wang, H. Li, Z.Q. Hu, J. Alloy Compd. 425 (2006) L1.

[5] Y.J. Zhou, Y. Zhang, Y.L. Wang, G.L. Chen, Appl. Phys. Lett. 90 (2007) 181904.

[6] A. Inoue, B.L. Shen, H. Koshiba, H. Kato, A.R. Yavari, Nat. Mater. 2 (2003) 661.

[7] Z. Bian, G. He, G.L. Chen, Scripta Mater. 43 (2000) 1003.

[8] G.Y. Wang, P.K. Liaw, Y. Yokoyama, W.H. Peter, B. Yang, M. Freels, R.A. Buchanan, C.T. Liu, C.R. Brooks, J. Alloy Compd. 434-435 (2007) 68.

[9] H. Choi-Yim, W.L. Johnson, Appl. Phys. Lett. 71 (1997) 3808.

[10] R.D. Conner, R.B. Dandliker, W.L. Johnson, Acta Mater. 46 (1998) 6089.

[11] C.C. Hays, C.P. Kim, W.L. Johnson, Phys. Rev. Lett. 84 (2000) 2901.

[12] C. Fan, R.T. Ott, T.C. Hufnagel, Appl. Phys. Lett. 81 (2002) 1020.

[13] J. Das, W. Loser, U. Kuhn, J. Eckert, S.K. Roy, L. Schultz, Appl. Phys. Lett. 82 (2003) 4690.

[14] D.C. Hofmann, J.Y. Suh, A. Wiest, G. Duan, M.L. Lind, M.D. Demetriou, W.L. Johnson, Nature 451 (2008) 1085.

[15] H. Tan, Y. Zhang, Y. Li, Intermetallics 10 (2002) 1203.

[16] H. Tan, Y. Zhang, D. Ma, Y.P. Feng, Y. Li, Acta Mater. 51 (2003) 4551.

[17] H. Tan, Y. Zhang, X. Hu, Y.P. Feng, Y. Li, Mater. Sci. Eng. A 375-377 (2004) 407

[18] Y. Zhang, W. Xu, H. Tan, Y. Li, Acta Mater. 53 (2005) 2607.

[19] C. Fan, A. Inoue, Appl. Phys. Lett. 77 (2000) 46.

[20] C. Fan, C.F. Li, A. Inoue, V. Haas, Phys. Rev. B 61 (2000) R3761.

[21] M.L. Lee, Y. Li, C.A. Schuh, Acta Mater. 52 (2004) 4121.

[22] J.W. Qiao, Y. Zhang, P.K. Liaw, Adv. Eng. Mater., in press, doi:10.1002/aem.200800149.

[23] C.T. Liu, L. Healtherly, D.S. Easton, C.A. Carmichael, J.H. Schneibel, C.H. Chen, J.L. Wright, M.H. Yoo, J.A. Horton, A. Inoue, Metall. Mater. Trans. A 29 (1998) 1811.

[24] J.J. Lewandowski, A.L. Greer, Nat. Mater. 5 (2006) 15.

[25] X.K. Xi, D.Q. Zhao, M.X. Pan, W.H. Wang, Y. Wu, J.J. Lewandowski, Phys. Rev. Lett. 94 (2005) 125510. 